\title{
REVIEW
}

\section{Cancer stem cells in the mammalian central nervous system}

\author{
G. J. Pilkington \\ Cellular and Molecular Neuro-oncology Research Group, Institute of Biomedical and Biomolecular Sciences, \\ School of Pharmacy and Biomedical Sciences, University of Portsmouth, St Michael's Building, White Swan Road, \\ Portsmouth PO1 2DT, UK
}

Received 8 July 2005; revision accepted 2 September 2005

\begin{abstract}
Malignant tumours intrinsic to the central nervous system (CNS) are among the most difficult of neoplasms to treat effectively. The major biological features of these tumours that preclude successful therapy include their cellular heterogeneity, which renders them highly resistant to both chemotherapy and radiotherapy, and the propensity of the component tumour cells to invade, diffusely, the contiguous nervous tissues. The tumours are classified according to perceived cell of origin, gliomas being the most common generic group. In the 1970s transplacental administration of the potent neurocarcinogen, N-ethyl-N-nitrosourea (ENU), enabled investigation of the sequential development of brain and spinal neoplasms by electron microscopy and immunohistochemistry. The significance of the primitive cells of the subependymal plate in cellular origin and evolution of a variety of glial tumours was thereby established. Since then, the development of new cell culture methods, including the in vitro growth of neurospheres and multicellular tumour spheroids, and new antigenic markers of stem cells and glial/neuronal cell precursor cells, including nestin, Mushashi-1 and CD133, have led to a reappraisal of the histological classification and origins of CNS tumours. Moreover, neural stem cells may also provide new vectors in exciting novel therapeutic strategies for these tumours. In addition to the gliomas, stem cells may have been identified in paediatric tumours including cerebellar medulloblastoma, thought to be of external granule cell neuronal derivation. Interestingly, while the stem cell marker CD133 is expressed in these primitive neuroectodermal tumours (PNETs), the chondroitin sulphate proteoglycan neuronal/glial 2 (NG2), which appears to denote increased proliferative, but reduced migratory activity in adult gliomas, is rarely expressed. This is in contrast to the situation in the histologically similar supratentorial PNETs. A possible functional 'switch' between proliferation and migration in developing neural tumour cells may exist between NG2 and ganglioside GD3. The divergent pathways of differentiation of CNS tumours and the possibility of stem cell origin, for some, if not all, such neoplasms remain a matter for debate and continued research, but the presence of self-renewing
\end{abstract}

Correspondence: Professor Geoffrey J. Pilkington, Cellular and Molecular Neuro-oncology Research Group, Institute of Biomedical and Biomolecular Sciences, School of Pharmacy and Biomedical Sciences, University of Portsmouth, St Michael's Building, White Swan Road, Portsmouth PO1 2DT, UK. Tel./Fax: +44 (0)23 92842116; E-mail: geoff.pilkington@port.ac.uk 


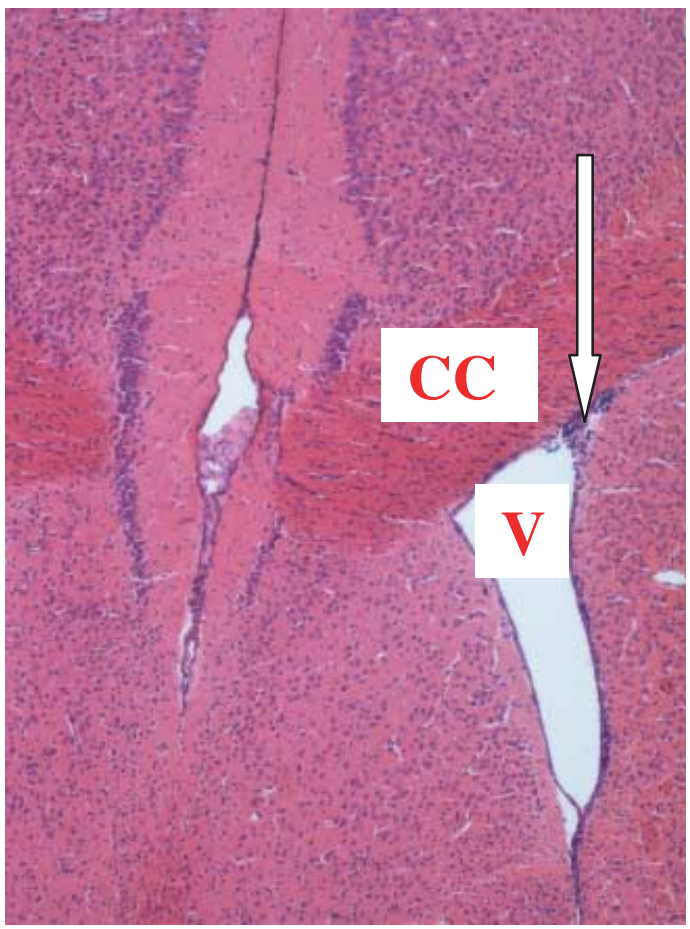

Figure 1. The open lateral ventricle (V) on the right of the coronal mouse brain section (left) with the corpus callosum (CC) white matter region above. The angle of the ventricle with the blue-stained subependymal plate is arrowed. Haematoxylin and eosin stain.

neural stem cells in the CNS of both children and adults strongly suggests a role for these cells in tumour initiation and resistance to current therapeutic strategies.

\section{INTRODUCTION}

Intrinsic brain tumours have historically been classified according to the type of cell from which they are thought to originate. Although tumours of neuronal type or lineage do occur, the gliomas are, by far, the most common group. In the 1970s developmental studies of tumourigenesis following transplacental administration of the potent neurocarcinogen, N-ethyl-N-nitrosourea (ENU) in rats, identified the significance of the primitive cells of subependymal plate (Fig. 1); the cellular origin and evolution of a variety of glial tumours were thereby established. Moreover, the presence of poorly differentiated stem cell populations throughout tumourigenesis and within pre-malignant lesions, microtumours, and overt neurologically apparent central nervous system (CNS) tumours has been identified (Lantos \& Pilkington 1979: Pilkington \& Lantos 1979). Since then, the following development of new transgenic brain tumour models, in vitro neurosphere and multicellular tumour spheroid models, and new antigenic markers of stem cells and glial/neuronal cell precursor cells, including nestin, Musashi-1 and CD133, the histological classification and origins of CNS tumours have been assessed in a new light. Not only are we gradually moving to a sound molecular basis for diagnostic and prognostic indication but there is a case for derivation 
of some, if not all, intrinsic brain tumours from transformed self-renewable neural stem cells. Indeed, such stem cells have been identified in medulloblastomas (Singh et al. 2003) and glioblastoma multiforme (Galli et al. 2004). Neural stem or precursor cells offer self-renewal ability, migration to areas causing pathological change within the nervous system and differentiate along functional glia and neuronal lineage (Shah et al. 2004). Immunocytochemical studies and semiquantitative reverse transcriptase (RT)-PCR on original tumour tissue and neurospheres derived from paediatric anaplastic astrocytoma, medulloblastoma, desmoplastic medulloblastoma and glioblastoma multiforme have revealed expression of neural stem cell-related genes including CD133 (see below), Musashi-1 (see below), Sox2 (an early neural stem cell transcription factor) and Bmi-1 (a polycomb group gene involved in self-renewal and proliferation of stem cells) (Hemmati et al. 2003). Transplantation of such cell populations may serve to replace damaged endogenous brain cells or maybe used as a vector system to deliver suitable agents to treat disease. Provision of exciting new therapeutic strategies for brain tumours by neural stem cell vectors includes delivery of the apoptotic TRAIL protein and bioluminescence tracking of the cells in pre-clinical animal systems. In one such report, neural stem cells were used to deliver cytosine deaminase (CD) to transplanted CNS-1 brain tumours in nude mice. Stem cells were either injected in close proximity to the tumour or far from it (contralateral hemisphere or caudal to lesion) or even injected systemically via the tail vein. In each case, the migratory stem cells, which had been retrovirally transduced with $\mathrm{CD}$, showed considerable tropism for the CNS-1 tumour, tracking into the lesion and 'chasing' invading neoplastic cells (Aboody et al. 2000). Further studies showed that xenografted brain tumours that received CD-transduced neural stem cells followed by treatment with 5-fluorouracil (5-FC) were reduced in size compared with similar 5-FC-treated tumours that had not received the neural stem cells (Aboody et al. 2000). This treatment modality has since been reported to show efficacy in the treatment of both intracranial and extracranial tumours of neural and non-neural origin in experimental model systems (Brown et al. 2003). It is also becoming apparent that, although existing therapies that kill non-stem cell tumour cells may reduce the tumour mass, resistant self-renewing tumour stem cells will regenerate the neoplasm. It is therefore thought that to radically improve outcome in malignant cancer therapies that kill, induce differentiation or prevent invasion/ metastasis of cancer stem cells would be of considerable value (Pardal et al. 2003).

\section{Primary brain tumours}

Primary or intrinsic CNS tumours arise from the substance of the brain and spinal cord. They are classified (Kleihues \& Cavenee 2000) according to the perceived cell of origin, generally the glial cells (astrocytes, ependymal cells, oligodendrocytes). Neuronally derived tumours do occur but are less frequent and generally seen in paediatric patients. The gliomas therefore predominate with the most malignant form, the glioblastoma, being the most common brain tumour in adulthood. Tumours are graded from I to IV in increasing malignancy, based on the observation of microscopic features including mitosis, nuclear atypia, microvascular proliferation and necrosis, although the so-called 'benign' grades I and II generally progress, with associated genetic aberrations, to high grade tumours with the passage of time. In addition, the location of even histologically benign tumours, within both the cranium and the eloquent brain regions, can prove fatal and so these neoplasms should be considered as, at least potentially, 'biologically' malignant. High-grade gliomas are generally well vascularized and show considerable morphological and antigenic cellular heterogeneity, a feature that results in differential chemo- and radio-sensitivity between subpopulations of tumour cells. These subpopulations can also communicate via paracrine growth factor mechanisms to influence proliferation and migration and thereby drive malignant potential (Pilkington 1992). Perhaps the major 
biological feature of gliomas, which precludes successful therapy, is their propensity for diffuse infiltrative invasion of the contiguous brain (Pilkington 1994; Bolteus et al. 2001). This is, perhaps, surprising because these tumours rarely metastasize to distant organs and tissues. In childhood, low-grade malignancy astrocytomas are the most common forms of brain tumour followed by the medulloblastoma, a highly malignant neoplasm that generally arises in the cerebellum and is thought to originate from external granule neurone lineage. Although malignant, around $60 \%$ of these are successfully treated. The marked cellular heterogeneity of malignant gliomas includes the presence of different populations of tumour cells that differ in their ability to form tumours and to perpetuate tumour growth and malignant progression. The majority of these tumour cells have a restricted ability to divide - as evidenced by the relatively low labelling index of these neoplasms - but a population of tumour stem cells that is able to extensively proliferate and form new foci of tumours may be identified on the basis of stem cell marker expression. Moreover, pathways that regulate the self-renewal of normal stem cells may be deregulated in cancer stem cells, resulting in continuous expansion of the self-renewing cancer stem cell population and resultant tumour formation. Agents that target the defective self-renewal pathways in cancer cells may lead to improvements in treatment of these neoplasms (Al-Hajj \& Clarke 2004).

\section{ENU carcinogenesis}

The simple nitrosamide, ENU is a potent neurocarcinogen that has been used to produce experimental CNS tumours in laboratory rats (Pilkington \& Lantos 1990). These tumours share morphological and biological similarities with naturally occurring, spontaneous neural neoplasms in human and other mammals. In particular, they have proved valuable in studies of the infiltrative/invasive edge of the tumour, where interaction with contiguous brain occurs, and in sequential studies of tumour development. While most ENU-induced tumours are mixed, or pleomorphic, gliomas, both oligodendroglioma and schwannoma also occur and fine-structural studies have demonstrated the presence of neuroblasts in some lesions (Lantos \& Pilkington 1977). In rats treated transplacentally with ENU, it was noted that resultant tumours presented predominantly adjacent to the lateral ventricles in the subependymal plate. On histological and ultrastructural analysis of 8-week post-natal rats, small foci of abnormal cell clusters composed of undifferentiated subependymal plate type cells with a high nuclear-cytoplasmic ratio, sparse cell organelles and a dominance of free over membrane-bound ribosomes were seen. A comprehensive light and electron microscopic study of the brains of rats whose mothers had received ENU on the 16th day of gestation revealed such early lesions from 8 weeks, well before the neurological signs of neoplasia became manifest at around 245 days post-natally. The lesions occurred frequently at the angle of the lateral ventricles between the corpus callosum and the caudate nucleus, the lateral aspect of the ventricles and within the subcortical white matter adjacent to the hippocampus (Lantos \& Pilkington 1979). The cells were clustered around both cerebral capillaries and neurones. By 16-20 weeks of age micro-tumours were detected, which were composed of a high proportion of subependymal plate stem cells together with glioblasts and various developing glia. Astrocytic, oligodendroglial and ependymal differentiation were all seen (Pilkington \& Lantos 1979). This pleomorphic cell population may arise as a result of the divergent processes of differentiation and anaplasia or may signify derivation from different stem/progenitor cell populations.

\section{Neurosphere and tumour spheroid culture}

The development and introduction of chemically defined culture media and the use of cellconditioned growth media, together with the use of three-dimensional cell culture systems, have 
permitted studies on the interaction between various cell populations. The variety of techniques that can be used to produce multicellular tumour spheroids and reaggregated brain cells has permitted complex studies on the interaction between neoplastic and non-neoplastic elements. In particular, these systems have been used to study brain tumour invasion (Corcoran et al. 2003). In addition, neurospheres may be produced from clonal cell populations of neural stem and progenitor cells that may then be grown under culture conditions that favour development along various lineage pathways (Svendsen et al. 1998) and characterized by use of a range of cell-specific and lineage-stage-specific antibodies. Although much knowledge can be gleaned from such in vitro approaches, interestingly, it has been reported that stem-like neural progenitors, isolated from glioblastoma seen to be multipotent in vitro, and differentiating along astroglial, oligodendroglial or neuronal pathways, emerged as unipotent in vivo, showing only astrocytic differentiation (Galli et al. 2004).

\section{Signalling pathways in stem cell renewal and tumourigenesis}

Although it remains to be fully established as to whether neural tumours arise from the transformation of stem cells or other differentiated or progenitor cell populations, various signalling pathways have been discovered, which are common to CNS tumours and neural stem cells. These include the Wnt and sonic hedgehog (Shh) in both medulloblastoma and glioma, PTEN in glioma and possibly the Notch pathway (Reya et al. 2001; Pardal et al. 2003).

\section{Stem cell antigenic markers}

Biological markers, in particular antigenic markers defined by immunocytochemistry, immunohistochemistry and flow cytometry, have played a significant role in the characterization and classification of CNS and have helped in assessing their biological behaviour as well as serving as prognostic indicators (Pilkington \& Lantos 1994). Now, further markers are proving to provide major tools with which to study stem and progenitor cells within the CNS. Among the antibodies that are of value in detecting stem cell populations and determining lineage pathway with subsequent differentiation in the CNS are nestin, Mushashi-1, CD44 and CD133.

\section{Nestin}

Nestin is an intermediate filament protein expressed by undifferentiated cells in the developing mammalian brain. Post-natally, it is restricted to the subventricular zone and vascular endothelium. It is present, however, in early ENU-induced neural neoplasia in undifferentiated, proliferating cell populations (Jang et al. 2004) and has been demonstrated in paediatric brain tumours (Almqvist et al. 2002) as well as cultures derived from supratentorial primitive neuroectodermal tumours (sPNETs) (Fults et al. 1992).

\section{Musashi-1}

Musashi-1 (Kaneko et al. 2000) is a neural RNA-binding protein that is strongly expressed in both fetal and adult mammalian neural stem cells (Okano et al. 2005). It is a member of the evolutionarily conserved Musashi family of RNA-binding proteins originally described in Drosophila and contributes to self-renewal of neural stem cells in connection with the Notchsignalling pathway. Recent reports using Musashi-1 immunostaining have suggested derivation of human paediatric CNS tumours from the subventricular zone (Uchida et al. 2004).

\section{CD44}

CD44 is a cell adhesion molecule, originally described as the lymphocyte-homing receptor, which has two isoforms with respective molecular weights of $80-90 \mathrm{kDa}$ and $150 \mathrm{kDa}$. The 
lower molecular weight isoform mediates attachment to hyaluronic acid (HA), which is present in relatively high concentration within the CNS. CD44 is expressed by normal, reactive and neoplastic astrocytes and is over-expressed in CNS tumours (Pilkington et al. 1993; Rooprai et al. 1999); it mediates glioma cell adhesion and invasion (Merzak et al. 1994a). Positive expression of CD44, along with non-expression or low expression of CD24 has been used as a tool in flow cytometric identification of cancer stem cells (Al-Hajj \& Clarke 2004).

\section{CD133}

CD133 is a $120-\mathrm{kDa}$ five-transmembrane cell surface protein that was originally described as a haematopoietic stem cell marker (Miraglia et al. 1997; Yin et al. 1997). More recently, however, it was shown to mark normal human neural stem cells (Uchida et al. 2000). Subsequently, Singh et al. (2003) demonstrated CD133 positivity by both immunohistochemistry and flow cytometry on two common forms of paediatric brain tumour - the high-grade malignancy medulloblastoma and the low-grade pilocytic astrocytoma. Moreover, brain tumour stem cells can be magnetic immuno-bead and fluorescence activated cell sorted by use of dissociated cell suspensions using CD133 antibodies. The subsequent CD133-positive selected subpopulation of tumour cells also expresses nestin but fails to express markers associated with differentiated cells of neural lineage (Singh et al. 2004a). Although these CD133/nestin-positive stem cells represent a minority fraction of the overall tumour cell complement, they are able to generate clonal tumour neurospheres in suspension culture. They also show increased self-renewal capacity and can be induced to differentiate into cells phenotypically similar to those seen in the original patient histology. The same group then developed an in vivo, serially transplantable, xenograft model in NOD-SCID (non-obese diabetic, severe combined immunodeficient) mouse brains by injecting as few as 100 CD133-positive brain tumour stem cells. The histological appearance of the resulting tumours resembled that of the original resected tumour. Conversely, injection of as many as $10^{5}$ CD133-negative cells failed to produce tumours (Singh et al. 2004b).

\section{Ganglioside GD3 and the neuronal/glial 2 (NG2) chondroitin sulphate proteoglycan}

Gangliosides are acidic glycosphingolipids characterized by the presence of sialic acid residues. They are ubiquitous in eukaryotes and are present in high concentration in the CNS. They can be located in the outer leaflet of the cell membrane and in tumour cells the rate of uptake and/ or shedding in the microenvironment surrounding the cellular membrane is greatly increased (Hakomori \& Handa 2002). Gangliosides are involved in the early developmental stages of the nervous system, during which time, simple gangliosides such as GD2, GM2, GD3 and GM3 are the predominant ganglioside 'species' (Kracun et al. 1992). As the transition to adulthood occurs, there is a shift in the ganglioside 'population' of the cell and more complex gangliosides predominate. In neoplastic tissues, simple gangliosides are over-expressed and once more become the most common gangliosides present in the cell. In particular, expression of GD3 ganglioside was found to be elevated in malignant astrocytomas (Traylor \& Hogan 1980). Indeed, the case for a transformed stem cell origin of glioma may be given additional support by the fact that antigens seen during embryological development yet lost on maturation are often highly expressed on brain tumours. For example, since GD3 is one of the major gangliosides expressed in embryological development, although it is not widely expressed in the mature CNS, in both medulloblastoma (Ladisch et al. 1997) and glioma (Knott et al. 1990), where it serves a potent role in modulation of cell migration and invasion (Merzak et al. 1995a), it is particularly highly expressed. Gangliosides are selectively localized in the cell membrane (Svennerholm 1963; Hakomori 1981) and cells with high migratory capacity concomitantly express more gangliosides and these are central to invasive behaviour of glial tumour cells (Merzak et al. 
1994a,b). Moreover, exogenous addition of gangliosides enhances the adhesion of human glioma cell lines to fibronectin, laminin, vitronectin and collagen I (Merzak et al. 1995b). Their role in tumour-tumour cell interactions, as well as the interactions between healthy cells and tumour cells, is pivotal, and their involvement in tumour growth, development and metastasis/ invasion is a key for these processes (Merzak et al. 1995a). Simple gangliosides such as GM3 and GD3 have been implicated as playing a major role in regulating the invasive potential of glial tumour cells. During the migratory phase of the invasion process, gangliosides have been seen to be up-regulated (Gratsa et al. 1997). Their role in mediation of invasion has been shown to occur via up-regulation of parameters regulating the invasion process such as extracellular matrices like laminin (Koochekpour et al. 1995) and matrix metalloproteinases (Maidment et al. 1996). Blocking of simple ganglioside GD3, either via antisense oligonucleotides targeting GD3 synthase (Zeng et al. 1999; Birkle et al. 2000) or by specific monoclonal antibodies (Hedberg et al. 2000), leads to a decrease in the growth of neuroblastoma, melanoma and glioma cells. GD3 may therefore not only be important in mediation of biological behaviour of developing neural elements but may also provide a suitable 'target' for therapy of certain forms of brain tumour.

NG2 is a membrane-spanning chondroitin sulphate proteoglycan that lacks any sequence homology with other proteoglycans. It has been proposed that, within the CNS of mammals, NG2 expression is associated with neural progenitors (oligodendrocyte or O-2A progenitors) or, perhaps, even a specific subset of glial cells (Nishiyama 2001; Butt et al. 2002) in the developing and adult mammalian brain and spinal cord. The expression of this chondroitin sulphate proteoglycan in adult primary brain tumours in human - as seen in ependymoma, oligodendroglioma, astrocytoma and glioblastoma multiforme (Chekenya et al. 1999: Shoshan et al. 1999) - may, however, serve not only as an indicator of the cellular origin of such neoplasms, but may also be associated with biological behaviour. In particular, NG2-expressing cells showed differences in their ability to adhere to and migrate on various substrates when compared with their negative counterparts.

NG2-positive glioma cells also proliferated more rapidly but migration was impaired. NG2 proteoglycan also promotes angiogenesis-dependent CNS tumour growth by sequestration of angiostatin (Chekenya et al. 2002a). The potential role of NG2 as a prognostic indicator and therapeutic target is of some considerable significance in the field of neuro-oncology. NG2 was also seen in MNU-induced transformed adult rat brain cells (Kokkinakis et al. 2001), transplantable, ENU-induced transplantable, rat brain tumours and in xenografted human glioma (Chekenya et al. 2002a). In these animal models, NG2 appears to confer a growth advantage and plays a role in glioma angiogenesis. PDGF-alpha receptor and NG2 are co-expressed on malignant glioma cells and blocking PDGF-alpha receptor results in diminution of NG2 expression and reduced growth of tumour cells (Chekenya \& Pilkington 2002). In addition, when NG2 expression was examined in histological sections from a series of 65 paediatric brain tumours (sPNETs, medulloblastoma and pilocytic astrocytoma) and flow cytometry and immunocytochemistry were carried out on selected cases in vitro interestingly, NG2 expression was high on low-grade malignancy pilocytic astrocytoma, a group of tumours with a low growth index (Bolteus et al., submitted). There was also differential expression between two histologically similar tumours of putative neuronal origin: sPNETs (generally NG2-positive, Fig. 2) and cerebellar medulloblastoma (generally NG2-negative). Curiously, although NG2 is expressed on brain tumour neovasculature by pericytes (Chekenya et al. 2002b), there appears to be no such expression within sPNETs, although tumour cells are frequently positive (Pilkington, 2005).

The ganglioside GD3 is also expressed on both animal and human gliomas and medulloblastomas and a case has been made for mutual exclusivity between NG2 and GD3 on the same 


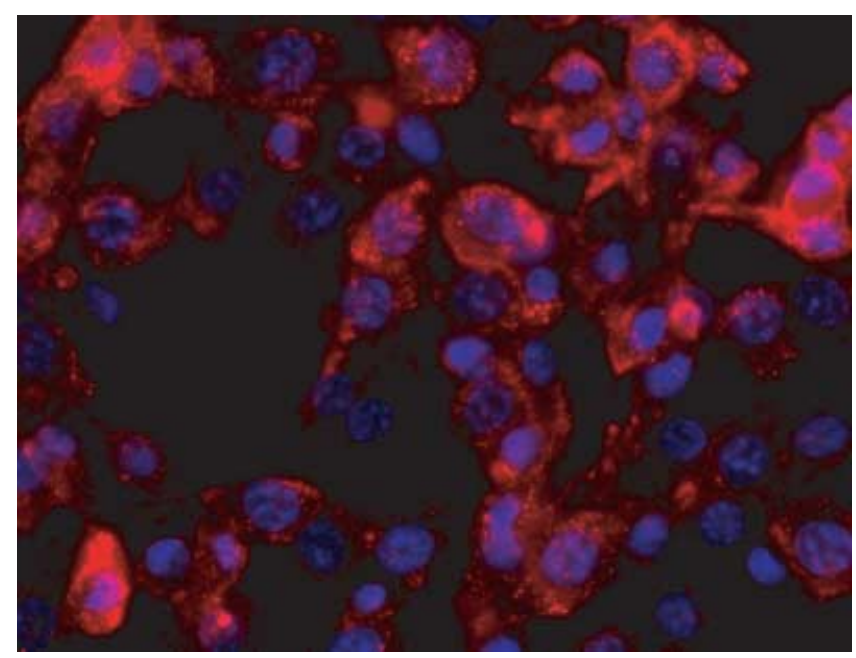

Figure 2. NG2-positive cells (Texas Red) from a surface-adherent sPNET culture. DAPI nuclear counterstain (blue).

population of tumour cells, the former conferring invasive behaviour whereas the later corresponds to proliferative activity (Chekenya \& Pilkington 2002).

Although NG2-positive cells are seen in normal mammalian cerebellum, their presence in medulloblastomas (postulated to originate from external granule neurone lineage) is not apparent (Pilkington, 2005). Since CD133 is also seen in medulloblastomas (Singh et al. 2004a), it may be that CD133 transformed stem cells do not progress to be NG2-positive in neoplasms of the CNS. If a progression from CD133-positive to NG2-positive cells could be shown in sPNETs, this may provide further evidence for differences in cellular origin for sPNETs and Medulloblastomas.

\section{CONCLUSIONS}

The identification of stem cell populations within both neoplastic and non-neoplastic CNS tissues in both children and adults supports the role for these cells in CNS tumour initiation. Indeed, in the light of these observations, the notion of gliomas developing from carcinogenchallenged post-mitotic/quiescent astrocytes seems to represent a far less likely scenario. Moreover, the reported increase in incidence of paediatric brain tumours and the significant increase in brain tumours in the elderly (Pilkington 2001) make the hypothesis of brain tumours arising in older people from quiescent neural stem cells that transform and proliferate in response to inflammatory activities of microglia and neuroglial cells (Seyfried 2001) quite plausible. While the identification of the precise lineage pathways taken during neural tumourigenesis will contribute to histological diagnosis and possibly to prognostic indication, the possible value in provision of new therapeutic regimens cannot be stressed enough. The high degree of cellular heterogeneity of malignant, intrinsic CNS tumours and their resistance to radio- and chemotherapeutic regimens render them among the most challenging group of neoplasms still to be overcome. The probable advent of novel therapies targeting cancer stem cells may finally provide an improved outcome for patients suffering from this devastating group of tumours. 


\section{REFERENCES}

Aboody KS, Brown A, Rainov NG, Bower KA, Liu S, Yang W, Small JE, Herrlinger U, Ourednik V, Black PMcL, Breakefield XO, Snyder EY (2000) Neural stem cells display extensive tropism for pathology in adult brain: evidence from intracranial gliomas. Proc. Natl Acad. Sci. U S A 97, 12864-12851.

Al-Hajj M, Clarke MF (2004) Self-renewal and solid tumor stem cells. Oncogene 23, 7274-7282.

Almqvist PM, Mah R, Lendahl U, Jacobsson B, Hobson G (2002) Immunohistochemical detection of nestin in paediatric brain tumours. J. Histochem. Cytochem. 50, 147-158.

Birkle S, Gao L, Zeng G, Yu RK (2000) Down-regulation of GD3 ganglioside and its O-acetylated derivative by stable transfection with antisense vector against GD3-synthase gene expression in hamster melanoma cells: effects on cellular growth, melanogenesis, and dendricity. J. Neurochem. 74, 547-554.

Bolteus AJ, Berens ME, Pilkington GJ (2001) Migration and invasion in brain neoplasms. Curr. Neurol. Neurosci. Rep. 1, 225-232.

Bolteus AJ, Parker K, Pilkington GJ (Submitted for publication) The expression and possible significance of the chondroitin sulphate proteoglycan, NG2, in paediatric brain tumours. (Submitted for publication.)

Brown AB, Yang W, Schmidt NO, Carroll R, Leishear KK, Rainov NG, Black PM, Breakefield XO, Aboody KS (2003) Intravascular delivery of neural stem cell lines to target intracranial and extracranial tumors of neural and non-neural origin. Human Gene Ther. 14, 1777-1785.

Butt AM, Kiff J, Hubbard P, Berry M (2002) Synantocytes: new functions for novel NG2 expressing glia. J. Neurocytol. 31, 551-565.

Chekenya M, Pilkington GJ (2002) NG2 precursor cells in neoplasia: functional, histogenesis and therapeutic implications for malignant brain tumours. J. Neurocytol. 31, 507-521.

Chekenya M, Rooprai HK, Davies D, Levine JM, Butt AM, Pilkington GJ (1999) The NG2 chondroitin sulphate proteoglycan: role in malignant progression of human brain tumours. Int. J. Dev. Neurosci. 17, 421-435.

Chekenya M, Hjelstuen M, Enger PO, Thorsen F, Jacob AL, Probst B, Haraldseth O, Pilkington G, Butt A, Levine JM, Bjerkvig R (2002a) NG2 proteoglycan promotes angiogenesis-dependent tumor growth in the central nervous system by sequestering angiostatin. FASEB J. (published online, 12 February) 16, 586-588.

Chekenya M, Enger PO, Thorsen F, Read T-A, Furmanek T, Mahesparan R, Tysnes BB, Levine JM, Al-Sarraj S, Butt AM, Pilkington GJ, Bjerkvig R (2002b) The glial progenitor proteoglycan, NG2, is expressed on angiogenic neovasculature by vascular pericytes in human malignant brain tumours. Neuropathol. Appl. Neurobiol. 28, 367380 .

Corcoran A, De Ridder LIF, Del Duca D, Kalala OJP, Lah T, Pilkington GJ, Del Maestro RF (2003) A review of in vitro brain tumour invasion models. Acta Neurochir. 145, 819-824.

Fults D, Pendone CA, Morse HG, Rose JW, McKay RDG (1992) Establishment and characterization of a human primitive neuroectodermal tumour cell line from the cerebral hemisphere. Lab. Invest. 66, 303-313.

Galli R, Binda E, Orfanelli U, Cipelletti B, Gritti A, De Vitis S, Fiocco R, Foroni C, Dimeco F, Vescovi A (2004) Isolation and characterization of tumorigenic, stem-like neural precursors from human glioblastoma. Cancer Res. 64, 7011-7021.

Gratsa A, Rooprai HK, Rogers JP, Martin KK, Pilkington GJ (1997) Correlation of expression of NCAM and GD3 ganglioside to motile behaviour in neoplastic glia. Anticancer Res. 17, 4111-4117.

Hakomori S (1981) Glycosphingolipids in cellular interaction, differentiation and oncogenesis. Annu. Rev. Biochem. 50, 733-764.

Hakomori S, Handa K (2002) Glycosphingolipid-dependent cross-talk between glycosynapses interfacing tumour cells with their host cells: essential basis to define tumour malignancy. FEBS Lett. 531, 88-92.

Hedberg KM, Dellheden B, Wikstrand CJ, Fredman P (2000) Monoclonal anti-GD3 antibodies selectively inhibit the proliferation of human malignant glioma cells in vitro. Glycoconj. J. 17, 717-726.

Hemmati HD, Nakano I, Lazareff JA, Masterman-Smith M, Geschwind DH, Bronner-Fraser Kornblum HI (2003) Cancerous stem cells can arise from pediatric brain tumors. Proc. Natl Acad. Sci. U S A 100, 15178-15183.

Jang T, Litofsky NS, Smith TW, Ross AH, Recht LD (2004) Aberrant nestin expression during ethylnitrosourea (ENU)induced neurocarcinogenesis. Neurobiol. Dis. 15, 522-544.

Kaneko Y, Sakakibara S, Imai T, Suzuki A, Nakamura Y, Sawamoto K, Ogawa Y, Toyama Y, Miyata T, Okano H (2000) Musashi 1: an evolutionarily conserved marker for CNS progenitor cells including neural stem cells. Dev. Neurosci. 22, 139-153.

Kleihues P, Cavenee WK, eds (2000) Pathology and Genetics of Tumours of the Nervous System. Lyon, France: IACR. ISBN 9283224094.

Knott JCA, Edwards AJ, Gullan RW, Clarke TM, Pilkington GJ (1990) A human glioma cell line retains expression 
of GFAP and gangliosides recognised by A2B5 and LB1 antibodies, after prolonged passage. Neuropathol. Appl. Neurobiol. 16, 489-500.

Kokkinakis DM, Watson ML, Honig LS, Rushing EJ, Mickey BE, Schold SC Jr (2001) Characterization of initiated cells in N-methylnitrosourea-induced carcinogenesis of the CNS in the adult rat. Neuro-oncology 3, 99-112.

Koochekpour S, Merzak A, Pilkington GJ (1995) Growth factors and gangliosides stimulate laminin production by glioma cells in vitro. Neurosci. Lett. 186, 53-56.

Kracun I, Rosner H, Drnovsek V, Vukelic Z, Cosovic C, Trbojevic-Cepe M, Kubat M (1992) Gangliosides in human brain development and aging. Neurochem. Int. 20, 421-431.

Ladisch S, Chang F, Li R, Cogen P, Johnson D (1997) Detection of medulloblastoma and astrocytoma-associated ganglioside GD3 in cerebrospinal fluid. Cancer Lett. 120, 71-78.

Lantos PL, Pilkington GJ (1977) Neuroblasts in cerebral tumours induced by ethylnitrosourea in rats: a fine structural study. Virchows Archiv. B Cell Pathol. 25, 243-259.

Lantos PL, Pilkington GJ (1979) The development of experimental brain tumours: a sequential light and electron microscope study of the subependymal plate. I. Early lesions (abnormal cell clusters). Acta Neuropathol. (Berlin) 45, $167-175$.

Maidment SL, Merzak A, Koochekpour A, Rooprai A, Rucklidge GJ, Pilkington GJ (1996) The effect of exogenous gangliosides on matrix metalloproteinase secretion by human glioma cells in vitro. European J. Cancer 32, 868-871.

Merzak A, Koochekpour S, Pilkington GJ (1994a) CD44 mediates human glioma cell adhesion and invasion in vitro. Cancer Res. 54, 3988-3992.

Merzak A, Koochekpour S, Pilkington GJ (1994b) Cell surface gangliosides are involved in the control of human glioma cell invasion in vitro. Neurosci. Lett. 177, 44-46.

Merzak A, Koochekpour S, McCrea S, Roxanis Y, Pilkington GJ (1995a) Gangliosides modulate proliferation, migration and invasiveness of human brain tumour cells in vitro. Mol. Chem. Neuropathol. 24, 121-135.

Merzak A, Koochekpour S, Pilkington GJ (1995b) Adhesion of human glioma cell lines to fibronectin, laminin, vitronectin and collagen I is modulated by gangliosides in vitro. Cell Adhes. Commun. 3, 27-43.

Miraglia S, Godfrey W, Yin AH, Atkins K, Warnke R, Holden JT, Bray RA, Walere EK, Buck DW (1997) A novel five-transmembrane hematopoietic stem cell antigen: isolation, characterization, and molecular cloning. Blood $\mathbf{9 0}$, 5013-5021.

Nishiyama A (2001) NG2 cells in the brain: a novel glial cell population. Hum. Cell 14, 77-82.

Okano H, Kawahara H, Toriya M, Nakao K, Shibata S, Imai T (2005) Function of RNA-binding protein Musashi-1 in stem cells. Exp. Cell Res. 306, 349-356.

Pardal R, Clarke MF, Morrison SJ (2003) Applying the principles of stem-cell biology to cancer. Nature Rev. 3, 895902.

Pilkington GJ (1992) Glioma heterogeneity in vitro: the significance of growth factors and gangliosides. Neuropathol. Appl. Neurobiol. 18, 434-442.

Pilkington GJ (1994) Tumour cell migration in the CNS. Brain Pathol. 4, 157-166.

Pilkington GJ (In Press 2005) The NG2 chondroitin sulphate proteoglycan: significance for the pathogenesis and behaviour of intrinsic brain tumours. J. Anatomy.

Pilkington GJ (2001) Brain tumours in the elderly. In: Duckett S, De La Torre JC, eds. Pathology of the Aging Human Nervous System, 2nd edn, pp. 408-428. New York: Oxford University Press Inc.

Pilkington GJ, Lantos PL (1979) The development of experimental brain tumours: a sequential light and electron microscope study of the subependymal plate. II. Microtumours. Acta Neuropathol. (Berlin) 45, 177-185.

Pilkington GJ, Lantos PL (1990) Pathology of experimental brain tumours. In: Thomas DGT, ed. Neuro-oncology. Primary Malignant Brain Tumours, pp. 51-76. London: Hodder Arnold.

Pilkington GJ, Lantos P (1994) Biological Markers for Tumours of the Brain. In: Simon L, Strong AJ, eds. Advances and Technical Standards in Neurosurgery, pp. 3-41. New York: Springer-Verlag.

Pilkington GJ, Akinwunmi J, Ognjenovic N, Rogers JP (1993) Differential binding of anti-CD44 on human gliomas in vitro. Neuroreport 4, 259-262.

Reya T, Morrison SJ, Clarke MF, Weissman IL (2001) Stem cells, cancer, and cancer stem cells. Nature 414, $105-111$.

Rooprai HK, Liyanage K, King A, Davies D, Martin K, Pilkington GJ (1999) CD44 expression in human meningiomas: an immunocytochemical, immunohistochemical and flow cytometric analysis. Int. J. Oncol. 14, 855-860.

Seyfried TN (2001) Perspectives on brain tumor formation involving macrophages, glia and neural stem cells. Perspec. Biol. Med. 44, 263-282.

Shah K, Hsich G, Breakefield XO (2004) Neural precursor cells and their role in neuro-oncology. Dev. Neurosci. 26, 118-130.

Shoshan Y, Nishiyama A, Chang A, Mork S, Barnett GH, Cowell JK, Trapp BD, Staugaitis SM (1999) Expression of oligodendrocyte progenitor cell antigens by gliomas: implications for the histogenesis of brain tumors. Proc. Natl Acad. Sci. U S A 96, 10361-10366. 
Singh SK, Clarke ID, Terasaki M, Bonn VE, Hawkins C, Squire J, Dirks PB (2003) Identification of a cancer stem cell in human brain tumours. Cancer Res. 63, 5821-5828.

Singh SK, Clarke ID, Hide T, Dirks PD (2004a) Cancer stem cells in nervous system tumours. Oncogene 23, 7267-7273.

Singh SK, Hawkins C, Clarke ID, Squire JA, Bayani J, Hide T, Henkelman RM, Cusimano MD, Dirks PB (2004b) Identification of human brain tumour initiating cells. Nature 432, 396-401.

Svendsen CN, ter Borg MG, Armstrong RJ, Rosser AE, Chandran S, Ostenfeld T, Cauldwell MA (1998) A new method for the rapid and long term growth of human neural precursor cells. J. Neurosci. Meth. 85, 141-152.

Svennerholm L (1963) Chromatographic separation of human brain gangliosides. J. Neurochem. 10, 613-623.

Traylor TD, Hogan EL (1980) Gangliosides of human cerebral astrocytomas. J. Neurochem. 34, 126-131.

Uchida N, Buck DW, He D, Reitsma MJ, Masek M, Phan TV, Tsukamoto AS, Gage FH, Weissman IL (2000) Direct isolation of human central nervous system stem cells. Proc. Natl Acad. Sci. U S A 97, 15720-15725.

Uchida K, Mukai M, Okano H, Kawase T (2004) Possible oncogenicity of subventricular zone neural stem cells: case report. Neurosurgery 55, 977-978.

Yin AH, Miraglia S, Zanjani ED, Almeida-Porada G, Ogawa M, Leary AG, Olweus J, Kearney J, Buck DW (1997) AC133, a novel marker for human hematopoietic stem and progenitor cells. Blood 90, 5002-5012.

Zeng G, Li DD, Gao L, Birkle S, Bieberich E, Tokuda A, Yu RK (1999) Alteration of ganglioside composition by stable transfection with antisense vectors against GD3-synthase gene expression. Biochemistry 38, 8762-8769. 